\title{
TECLA. Revista de la Consejería de Educación en el Reino Unido e Irlanda
}

TECLA. Revista de la Consejería de Educación en el Reino Unido e Irlanda. 1/2020. Edición: mayo 2020. NIPO: 847-19-076-3. https://sede.educacion.gob.es/publiventa/tecla-n-12020-revistade-la-consejeria-de-educacion-en-el-reino-unido-e-irlanda/ensenanza-lengua-espanola/24016

\section{Reseña de Minia Porteiro Fresco}

\section{Universidad de Alcalá}

La revista TECLA es una revista digital publicada por la Consejería de Educación en el Reino Unido e Irlanda. Ha pasado por diferentes etapas y ha ido ampliando su propuesta a lo largo de los años, aunque su estructura original, formada por tres textos, una propuesta didáctica y los solucionarios correspondientes, se mantiene como parte esencial de la revista. La revista TECLA, tal y como la conocemos hoy, nació con el objetivo de convertirse en un "foro abierto para la comunidad educativa dedicada a la enseñanza y aprendizaje del español en el Reino Unido e Irlanda" ${ }^{77}$. Actualmente, se compone por secciones abiertas y no abiertas. En las abiertas, se recogen diferentes experiencias tanto del profesorado como de los centros que enseñan español en el Reino Unido e Irlanda, mientras que las no abiertas son elaboradas por el consejo asesor de la publicación. Además, desde el año 2006, la Consejería de Educación también ofrece de forma periódica una propuesta didáctica basada en artículos publicados en el diario EL PAÍS. Estos artículos se integraron en la revista en el año 2015 coincidiendo con el lanzamiento de la nueva versión.

La nueva revista TECLA contiene una estructura básica formada por ocho secciones. Comienza con una presentación de cada número dentro de la sección TECLAtaqra/Presentación. En segundo lugar, se ofrece la sección TECLAentrevista. En tercer lugar, se presentan las dos secciones abiertas: la primera de ellas es TECLAproyectos, destinada a que los centros educativos británicos e irlandeses den a conocer sus proyectos de enseñanza del español; y la segunda, TECLAprofesorado, dirigida a que los docentes compartan sus propuestas para el aula de español. Seguidamente, se incluyen las secciones TECLAcultura y TECLAclil. Por último, la revista acaba con dos secciones dedicadas al trabajo con textos (TECLAtextos y TECLApaís).

\footnotetext{
${ }^{77}$ https://www.educacionyfp.gob.es/reinounido/publicaciones-materiales/publicaciones.html
} 
Así, el número publicado en mayo de 2020 (1/2020) comienza con la sección TECLAtaqra. En esta sección el actual Consejero de Educación en el Reino Unido e Irlanda, José Benedicto Iruiñ, se encarga de presentar el número con un artículo que se titula GRACIAS. Su contribución pretende ser un homenaje a todo el colectivo docente por su labor durante el confinamiento vivido la pasada primavera por la COVID-19. El autor define la actuación de los docentes con estas palabras "nuestros docentes se han mostrado inasequibles al desaliento, constantes, tenaces y han superado las dificultades buscando la mejor manera de enseñar y de garantizar la formación de los alumnos, de garantizar su formación y la consecución de sus objetivos" (p. 5). Explica algunas de las dificultades a las que se enfrentaron y cómo fueron clave a la hora de favorecer y de preservar la igualdad de oportunidades del alumnado a pesar de vivir en condiciones familiares tan diversas. Por lo tanto, este número comienza con un merecido reconocimiento a uno de los colectivos protagonistas de la pandemia y potencial lector de la revista.

En la segunda sección, TECLAentrevista, Concha Julián de Vega, asesora técnica de la Consejería de Educación del Reino Unido, entrevista a la profesora Nazaret Pérez-Nieto, profesora del Departamento de Español de School of Modern Languages (MLANG) de la Universidad de Cardiff. La profesora cuenta cómo fue su trayectoria docente desde los inicios, con un lectorado de español en el Departamento de Español de la Facultad de Lenguas Modernas de la Universidad de Ulster, hasta llegar a su situación actual. Quizás uno de los aspectos más relevantes de la entrevista es su reflexión sobre la necesidad de establecer una relación estrecha entre el contexto universitario y la educación primaria y secundaria. Como ejemplo de este acercamiento entre los diferentes niveles educativos explica su colaboración con Routes into Languages Cymru, organización que promueve el aprendizaje de lenguas en el País de Gales a través de talleres a niños de primaria en las escuelas. Resulta una entrevista muy interesante que permite conocer de cerca la trayectoria profesional de una docente que se ha abierto camino en un país extranjero haciendo lo que más le gusta, enseñar español, y nos acerca la realidad de otro sistema universitario como el británico.

Y así llega la tercera sección, TECLAproyectos, que es una de las dos secciones abiertas de la revista. En este número cuenta con la colaboración de Eneida García Villanueva, licenciada en Traducción e Interpretación por la Universidad Autónoma de Barcelona y con experiencia docente en varios niveles y sectores en España, Inglaterra, Escocia y la República Checa. Para contextualizar su proyecto, comienza explicando el plan de estudios del sistema educativo escocés y su "Enfoque $1+2$ del aprendizaje de lenguas" (1+2 Approach to Language 
Learning) que se implantó en 2012. El programa establece como lenguas vehiculares el inglés y el gaélico escocés (L1) y promueve la introducción de una lengua adicional (L2) desde el primer curso de primaria hasta el tercer curso de secundaria y la incorporación de una segunda lengua (L3) en el quinto curso de primaria. Eneida García se muestra convencida de que en las aulas no se refleja la realidad multilingüe de los estudiantes. En este sentido, justifica la introducción del concepto de "translenguar" ${ }^{78}$ y destaca la importancia de acabar con la división entre la lengua escolar y la familiar. En este contexto, surgió el proyecto que presenta, la obra multilingüe All the World is Our Stage: primary pupils never lost in translanguaging, que refuerza la relación familia-escuela. La docente asegura que las actividades de translenguaje permiten identificar las lenguas que hablan los estudiantes en casa y favorecen que se sientan orgullosos de compartirlas en el colegio. Acaba el artículo asegurando que "el beneficio universal es que toda la clase pasa a reflexionar de manera consciente sobre el uso y la naturaleza de los idiomas, potenciándose así su conciencia metalingüística" (p. 13). Es un interesante proyecto con el que ha cosechado muy buenas críticas en todo el país. Una de las aportaciones más interesantes del artículo, además de la invitación a reflexionar sobre el concepto de "translenguar" y de cómo interpreta el multilingüismo en las aulas, es que ofrece la posibilidad de acceder ${ }^{79}$ a todos los recursos necesarios para aplicar el proyecto presentado.

Después del proyecto docente, empieza la segunda sección abierta, TECLAprofesorado, que recoge una propuesta didáctica para aplicarla en el aula de español. La presentan dos profesoras de español, Elena Alonso Torío y Beatriz Macía Vega colaboradoras del Instituto Cervantes de Manchester. La actividad se titula "Que Dios me libre... ¡De Internet!”, y tiene como objetivo trabajar los sentimientos y las emociones en la enseñanza secundaria, universitaria o de adultos. La propuesta se organiza en torno a tres tareas. La tarea 1, "Se dice el pecado, pero no el pecador", está formada por tres ejercicios orientados a trabajar la expresión oral, el vocabulario y activar los conocimientos previos sobre el tema. La tarea 2, "Quien esté libre de pecado, que tire la primera piedra”, comienza con la lectura de un texto, seguido por unos ejercicios de comprensión lectora; de léxico, a partir de campos semánticos y expresiones con significado metafórico; y de expresión oral, para poner

\footnotetext{
78 "El término trawsieithu ("translenguar") acuñado por Cen Williams en 1994 surgió del sistema bilingüe galés. Este profesor e investigador de metodologías didácticas creó y defendió dicho concepto como una habilidad bilingüe que acelera el desarrollo y la competencia de ambas lenguas. En el contexto escolar de inmersión bilingüe en el País de Gales se refiere a los procesos mediante los cuales el inglés y el galés se alternan con diferentes propósitos y finalidades en una misma clase" (p. 13).

${ }^{79}$ https://figshare.com/collections/All_the_World_is_Our_Stage_primary_pupils_never_lost_in_translanguagi $\underline{\mathrm{ng} / 4520597}$
} 
en práctica el nuevo vocabulario. La tarea 3, "Pagan justos por pecadores", se estructura en torno a una canción del músico Xoel López. Dentro de esta tarea, proponen ejercicios de comprensión auditiva y de gramática con el uso del presente e imperfecto del subjuntivo a partir de estructuras que expresen deseos posibles (presente del subjuntivo) y poco probables o improbables (imperfecto del subjuntivo). Por último, como tarea 4, "Dios te oiga ... ¡Cantar!", sugieren que los alumnos busquen canciones similares. Es una actividad muy completa, que engloba el trabajo de las cuatro habilidades comunicativas, plantea ejercicios de expresión y comprensión tanto oral como escrita combinado con el componente cultural. Asimismo, otro aspecto interesante es que la propuesta viene acompañada por el solucionario, lo que facilita su aplicación en el aula, puesto que ayuda a interpretar mejor tanto los objetivos como el enfoque de la actividad.

Una vez presentadas las dos secciones abiertas, la revista continúa con una propuesta cultural recogida en su sección TECLAcultura. Es el turno de Ana María Alonso Varela, asesora técnica de la Consejería de Educación en el Reino Unido e Irlanda, quien contribuye a la revista con el artículo titulado "Agenda 2021. Preparativos para hacer el Camino de Santiago desde Irlanda". Es un escrito en forma de diario, al que se dirige en segunda persona a lo largo de todo el texto para explicarle los preparativos del Camino de Santiago. Su comienzo es llamativo, puesto que empieza como si la autora acabara de tomar la decisión "Ya está decidido, en el verano de 2021, Año Santo Jacobeo, voy a hacer El Camino a pie saliendo desde Dublín" (p. 23) y continúa explicando qué es el Camino. La autora, además de contar cuáles son sus motivaciones personales para hacerlo, ofrece al lector varias páginas en las que puede encontrar información sobre las diferentes rutas y múltiples consejos. Con el avance del texto, Ana María Alonso va integrando varias tablas en las que aparece clasificado vocabulario por campos semánticos: qué llevar en la mochila, ropa, cosas propias del Camino, botiquín, objetos opcionales y elementos útiles. Al final del artículo, incluye una última tabla con más vocabulario específico del Camino, pero esta vez asociado a su definición. Un detalle clave del texto con un claro componente cultural es la alusión al poeta Antonio Machado "Caminante, no hay camino, se hace camino al andar" (p. 23 y 28), que nombra tanto al inicio como al final a modo de despedida del diario. Termina el artículo fiel al género textual elegido, asegurándole al diario que ha encontrado más información y que la compartirá otro día con él. Resulta una curiosa manera de presentar un tema cultural, interesante para introducir nuevo vocabulario y es un ejemplo de cómo incluir textos de géneros diferentes que permitan trabajar a la vez sus peculiaridades lingüísticas. 
A la sección cultural, le sigue TECLAclil, que tiene como objetivo presentar experiencias docentes de Aprendizaje Integrado de Contenidos y Lenguas Extranjeras, $\left(\mathrm{AICLE}^{80}\right)$. En este número se la dedican a una experiencia AICLE llevada a cabo por Sara Montero Vázquez, maestra y coordinadora de Lenguas Extranjeras y Nuevas Tecnologías en la Miles Coverdale Primary School de Londres. El artículo se centra, principalmente, en contar cómo ha vivido ella la experiencia concreta, pero está enfocada más desde el punto de vista personal que de la experiencia docente. No se aportan detalles sobre cómo plantea el trabajo dentro del aula ni pautas concretas o sugerencias que se puedan aplicar. Solamente, deja entrever que una de las principales dificultades a la hora de llevar a cabo una propuesta AICLE es que hay que crear todos los recursos desde cero, puesto que apenas existen materiales para enseñar una materia del currículum inglés en español y que esto requiere mucho esfuerzo y tiempo. Quizás lo más interesante es la información que ofrece sobre los materiales publicados por la Consejería de Educación dentro del apartado, CLIL: Para, chuta, gol (2009) y Corta, pega, pinta (2010); y también comenta que se está estudiando la posibilidad de generar un repositorio con recursos que hayan sido aplicados en el aula.

La séptima sección, TECLAtextos, es la que mantiene la esencia original de la revista, incluye un texto y su propuesta didáctica para trabajar en el aula de español, pero mientras que en la versión tradicional de la revista se ofrecían tres textos (uno para cada nivel de

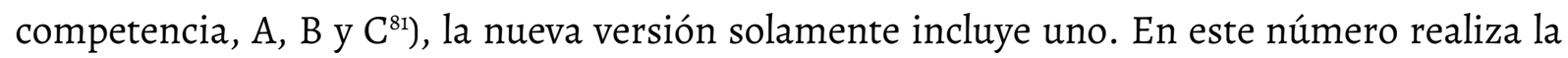
propuesta Carmen Santos, asesora técnica de la Consejería de Educación en el Reino Unido e Irlanda. El texto que ha escogido contiene alrededor de 400 palabras, está planteado para trabajar con estudiantes del nivel B y se titula "Cabezudos de Salamanca: ¡El Padre Lucas y la lechera...!". Tras el texto, la autora presenta una serie de actividades didácticas para antes y después de su lectura. Las primeras están orientadas a activar los conocimientos previos sobre el tema y a ayudar a contextualizarlo. Entre las actividades posteriores a la lectura se ofrecen ejercicios para facilitar la creación de inferencias relacionadas con el texto, valorar la comprensión lectora o ampliar el vocabulario (por campos semánticos y sinónimos). También se proponen ejercicios para trabajar la cohesión gramatical (con relativos y antecedentes) y el solucionario. Es una propuesta muy completa y bien planificada, combina el trabajo de comprensión y expresión escritas con el componente cultural. Al igual que en la sección TECLAprofesorado, la posibilidad de consultar el solucionario permite entender mejor los

\footnotetext{
${ }^{80}$ En inglés, CLIL: Content and Language Integrated Learning.

${ }^{81}$ Los textos del nivel A tienen alrededor de 200 palabras; los del nivel B, 400; y los del nivel C, 600 palabras.
} 
objetivos de la actividad y facilita la labor del profesorado que quiera aplicarla en su aula de español.

La revista pone fin a este número con la sección TECLApaís. El texto escogido se titula "Hombre con bata y pelo alborotado: el referente científico que hay que cambiar", fue escrito por Agathe Cortes y publicado en EL PAÍS el 11 de febrero de 2020 con motivo del día Internacional de la Mujer y la Niña en la Ciencia. Es un texto de 1300 palabras que pretende hacer reflexionar sobre la ausencia de referentes femeninos en el mundo de la ciencia, la necesidad de romper los estereotipos culturales y de reconocer el papel de la mujer en este ámbito. Además del texto se presentan seis sugerencias didácticas. Entre las actividades previas a la lectura, destaca la que invita al estudiante a investigar sobre el origen del día de las mujeres científicas. Como actividades posteriores a la lectura se propone sintetizar el texto y se proporciona el acceso a otro recurso, "Científicas, el cómic" ${ }^{82}$. A partir de aquí, se ofrecen actividades sobre el vocabulario nuevo y se sugiere a los estudiantes que busquen su equivalente en su lengua propia. Esta propuesta resulta interesante para despertar la conciencia metalingüística. En general, la propuesta se basa en ejercicios de comprensión lectora y expresión oral y escrita mediante el trabajo de búsqueda de información, reflexión, síntesis y de vocabulario. Es una propuesta diferente que permite trabajar aspectos socioculturales de actualidad a través de un texto publicado por un diario de gran difusión.

Tal y como se ha visto a lo largo de las diferentes secciones, TECLA es una revista que ofrece una gran variedad de recursos que permiten al profesorado de español mantenerse actualizado a través del conocimiento de diferentes proyectos y experiencias docentes, todo ello accesible de forma gratuita. Proporciona recursos y materiales muy completos, fáciles de introducir en el aula y con el solucionario como un recurso añadido y facilitador a la hora de aplicarlos, puesto que garantiza su correcta interpretación por parte de una tercera persona. Otra de las ventajas es que en los diferentes números se van ofreciendo materiales dirigidos a los tres niveles de competencia (A, B y C) y la posibilidad de trabajar con un artículo de actualidad a través de una sugerencia didáctica para los niveles más avanzados.

Como conclusión, hay que recordar que la red exterior del Ministerio de Educación y Formación Profesional publica desde 2004 una revista especializada en la enseñanza del Español como Lengua Extranjera (ELE), la revista redELE (ISSN 1571-4667). No obstante, para conocer la realidad específica de cada país, resulta muy interesante el trabajo que realizan las diferentes Consejerías de Educación. Cada consejería pone a disposición del profesorado de

\footnotetext{
${ }^{82}$ http://institucional.us.es/cientificas/wp-content/uploads/2020/01/comic_cient\%C3\%ADficas_small.pdf
} 
español materiales didácticos, divulgativos y publicaciones con el objetivo de facilitar información y acceso a herramientas al profesorado que trabaje en su país, pero que pueden ser igualmente útiles para todo el colectivo docente de español. Uno de estos recursos es la revista TECLA, pero en esta misma línea, encontramos otras revistas también de publicación gratuita como: Mediterráneo, revista de la Consejería de Educación en Italia, Grecia y Albania; la revista Azulejo para el aula de Español, de la Consejería de Educación en Portugal; Calanda, revista didáctico-cultural realizada por la Consejería de Educación de Francia; Materiales, de la Consejería de Educación en Estados Unidos, Canadá y otros países; entre otras revistas. Sus objetivos son servir de apoyo a la enseñanza de la lengua española en sus países. Cada publicación es diferente, pero permite al profesorado de español disponer de gran variedad de recursos didácticos y entender mejor la realidad específica cada país.

\section{Referencias bibliográficas}

Consejería de Educación en el Reino Unido e Irlanda (2020): TECLA. Revista de la Consejería de Educación en el Reino Unido e Irlanda, (1/2020). https://sede.educacion.gob.es/publivent a/tecla-n-12020-revista-de-la-consejeria-de-educacion-en-el-reino-unido-eirlanda/ensenanza-lengua-espanola/24016

Consejería de Educación en Estados Unidos y Canadá (2019): Materiales para la enseñanza multicultural, (27). https://sede.educacion.gob.es/publiventa/-materialespara-la-ensenanza-multicultural-n-27-explorando-horizontes-integrandoculturas/ensenanza-lengua-espanola/23410

Consejería de Educación en Francia (2019): Calanda. Revista didáctica de la acción educativa española en Francia, (15). https://sede.educacion.gob.es/publiventa/descarga.action?f_ codigo_agc $=21032$

Consejería de Educación en Italia, Grecia y Albania (2016): Mediterráneo. Revista de la Consejería de Educación en Italia, Grecia y Albania, (6). https://sede.educacion.gob.es/publiventa/de scarga.action?f_codigo_agc=18969

Consejería de Educación en Portugal (2019): Azulejo para el aula de español, (10). https://sede.educacion.gob.es/publiventa/azulejo-para-el-aula-de-espanol-n$\underline{10 / e n s e n a n z a-l e n g u a-e s p a n o l a / 23791}$

Ministerio de Educación y Formación Profesional (2019): RedELE, Revista Electrónica de Didáctica del Español como Lengua Extranjera, (31). https://sede.educacion.gob.es/publiv $\underline{\text { enta/descarga.action?f_codigo_agc }=2021}$ 